\title{
Effect of Low Load Resistance Blood Flow Restriction Training on Knee Osteoarthritis
}

\author{
MAI M.A. ABDALLAH, M.Sc.*; NADIA A. FAYAZ, Ph.D.**; MAHA M. MOHAMMED, Ph.D.** and \\ MOHIE ELDIN M. FADEL, M.D.***
}

The Department of Physical Therapy for Musculoskeletal Disorders and Their Surgeries *, **, Faculty of Physical Therapy, Pharos* \& Cairo** Universities and The Department of Orthopedic Surgery, Faculty of Medicine, Alexandria University***, Egypt

\begin{abstract}
Background: The initiation, progression, and severity of knee osteoarthritis (OA) have been associated with decreased muscular strength and alterations in joint biomechanics. Resistance exercise has been shown to be an effective intervention for decreasing pain, restoring muscle strength and joint mechanics while improving physical function in patients with knee OA. High-resistance exercise has been demonstrated to be more beneficial than low-resistance exercise. However, patients with knee OA may have reduced tolerance of high resistance training programs.
\end{abstract}

Aim of Study: The current study was conducted to assess whether concurrent application of blood flow restriction (BFR) to low load resistance (LLR) training is an efficient and tolerable mean of improving functional mobility in patients with knee OA.

Patients and Methods: Forty female patients with mild to moderate unilateral tibiofemoral OA. Their age ranged from 45-60 years old. All patients were referred by orthopedic surgeons who were responsible for diagnosis of OA based on clinical and radiological examination. All patients were randomly assigned into one of two groups: Group (A) This group included 20 patients underwent conventional high load resistance (HLR) training exercises (60\% 1RM), group (B) This group included 20 patients received LLR training exercises $(30 \% 1 \mathrm{RM})$ combined with BFR, three sessions per week for one month. The study was conducted from September 2017 to February 2018 in a private orthopedic and physical therapy center.

Evaluation: Timed up and go (TUG) test was used to assess patient's functional mobility. Results showed that both groups had significant improvement in functional mobility.

Conclusion: Both conventional HLR training and LLRBFR training are effective treatment options for improving functional mobility in patients with knee OA, However, the use of LLR-BFR training resulted in less anterior knee pain during sessions compared to high load training.

Correspondence to: Dr. Mai M.A. Abdallah, The Department of Physical Therapy for Musculoskeletal Disorders and Their Surgeries, Cairo Egypt
Key Words: Knee osteoarthritis - Blood flow restriction Strengthening exercises - TUG test.

\section{Introduction}

OSTEOARTHRITIS is a disabling disease that produces severe morbidity reducing physical activity [1]. It is the most common joint disorder and is among the main causes of disability in the elderly [2]. The knee is the most common weight-bearing joint affected by OA, with an estimated $45 \%$ of all adults at risk of developing knee OA in their lifetime [3].

One biomechanical factor that may significantly contribute to incident knee OA and progression of cartilage loss is quadriceps weakness [4]. Multiple studies have reported that individuals with knee OA have weak quadriceps muscles [5], and an observational study revealed that higher quadriceps strength protected against the development of knee OA [6].

Since the quadriceps, in addition to other lower limb muscles, are necessary for knee loading and stability during locomotion, increasing quadriceps muscle strength may result in increased physical function of those with or at risk of knee OA and decrease the incidence and/or progression of the disease [7].

The Osteoarthritis Research Society International (ORSI) recommended strength training as a possible treatment or a method to slow progression of knee OA [8].

There is reasonably large literature supporting the efficacy of resistance training in patients with knee OA. Many studies found knee OA symptoms, physical function, and strength improved with 
resistance training when compared with usual care [9].

Strength training, as recommended by the American College of Sports Medicine (ACSM), must be performed at a minimum resistance training load of $60 \%$ to $70 \%$ 1-repetition maximum (1RM) for strength gain and $70 \%$ to $85 \% 1 \mathrm{RM}$ for muscle hypertrophy [10]. Unfortunately, factors that confer elevated risk of knee OA (for example, obesity, knee pain, knee injury/surgery) also contribute to a perceived reduced tolerance of the high-load programs recommended for eliciting strength gains [11]. Thus, for reducing disease risk and enhancing physical function, there is a need for a means of effectively strengthening the quadriceps muscles while limiting pain and adverse joint loading in people with knee OA [7].

An alternative to traditional strength training that may be well tolerated by patients with knee OA is LLR-BFR training. Blood flow restriction is attained through administering pressure externally with a pneumatic cuff or tourniquet. The applied pressure occludes venous outflow while maintaining arterial inflow [12]

Blood flow restriction training also known as Kaatsu training, was pioneered by Yoshiaki Sato, of Japan in the 1970s and 1980s [13]. This training method involves decreasing blood flow to a muscle by application of an external constricting device to provide mechanical compression of the underlying vasculature. Blood flow restriction is applied with the intent to promote blood pooling in the capillary beds of the limb musculature distal to the tourniquet [13]

Blood flow restriction alone has been shown to attenuate the disuse atrophy during periods of immobilization; however, BFR must be combined with an exercise which enhances muscular development [14]. Resistance exercise appears to provide greater muscular gains when combined with BFR [13]. In further support of LLR-BFR, Loenneke et al., [15] concluded that it offered no greater risk than traditional exercise. Blood flow restriction has been combined with several types of exercise (e.g. knee extension, knee flexion, leg press, cycling, walking) and resulted in significant improvements in strength and physical function [16-18].

\section{Subjects and Methods}

The study design is a randomized controlled trial which was conducted from September 2017 to February 2018. Forty female patients with mild to moderate unilateral tibiofemoral $\mathrm{OA}$, their age ranged from 45-60 years; the participants were selected from a private orthopedic and physical therapy center in Alexandria. Before enrollment in the study patients signed an informed consent.

Patients were excluded if they had bilateral knee OA, Congenital or acquired inflammatory or neurological (systemic or local) diseases involving the knee,Repeated treatment with steroids, Patients who had received joint replacement surgery in either Knee and/or a hip and patients with cardiovascular disorders.

All patients were randomly assigned to one of two groups (A and B) of equal number, using opaque sealed envelopes. Group A included 20 patients who received conventional HLR training exercises. Group B included 20 patients who received LLR-BFR training.

The training load in each group has been adjusted according to the 1RM test [19]. The load during quadriceps exercises in the conventional group was standardized to $60 \%$ of the estimated 1-repetition maximum (1-RM) and the load in the BFR group was standardized to $30 \%$ of the $1-\mathrm{RM}$ associated with BFR [20].

\section{Assessment procedures:}

Functional mobility has been assessed using TUG test. Participant was asked to stand up, walk to a mark $3 \mathrm{~m}$ away, turn around and return to sit back in the chair at their regular pace. Regular walking aid was allowed and recorded. Same chair is needed for re-testing.

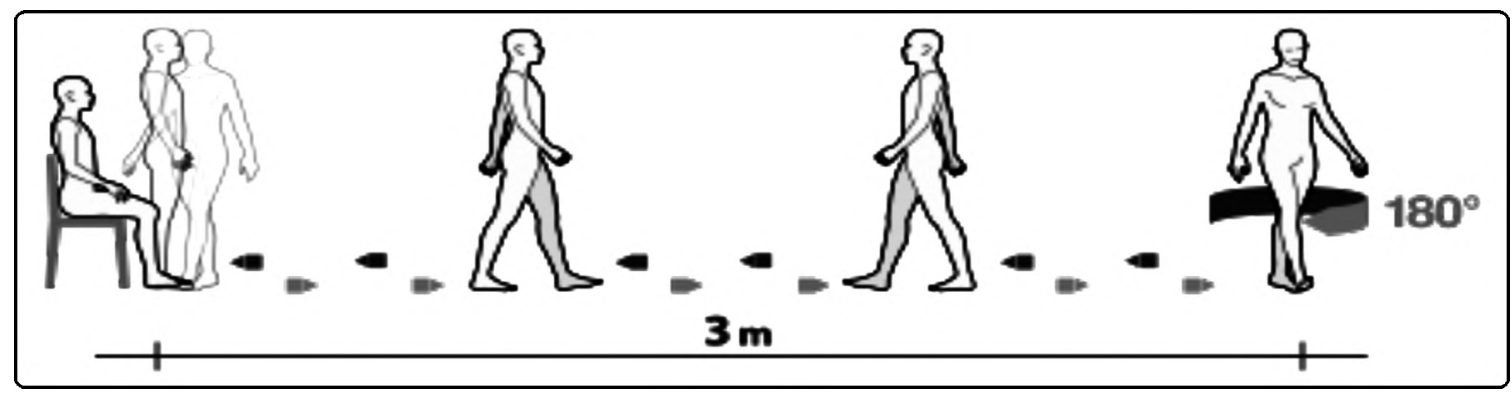

Fig. (1): Timed up and go test adopted from Gautschi et al., [21]. 


\section{Treatment procedures:}

Throughout the intervention, each training session was preceded by $10 \mathrm{~min}$ of general warm up. The maximum load for all strengthening exercises $(60 \%$ of the 1-RM in the conventional group and $30 \%$ of 1-RM in the BFR group) was evaluated during the first treatment session and reviewed weekly in order to make any necessary adjustments. Resistance was progressively increased as strength improves. Exercise load was adjusted each session according to the 1RM test. The patients performed exercises during physical therapy and did not perform exercises at home.
One-repetition maximum (1-RM) Estimation:

Maximum load with which 1 repetition of the exercise could be completed without pain (using a knee extension amplitude between $90^{\circ}$ and $0^{\circ}$ of knee flexion. Patient performed up to five attempts of a unilateral knee extension (dominant limb). This exercise was done using ankle weights and progressed to a knee extension machine based on the patient's tolerance with intervals of three to five minutes between attempts. The 1RM test was performed as a pre-test and the training load is then adjusted accordingly [19]. These criteria were based on the protocol of a previous study by the American college of sports medicine [22].

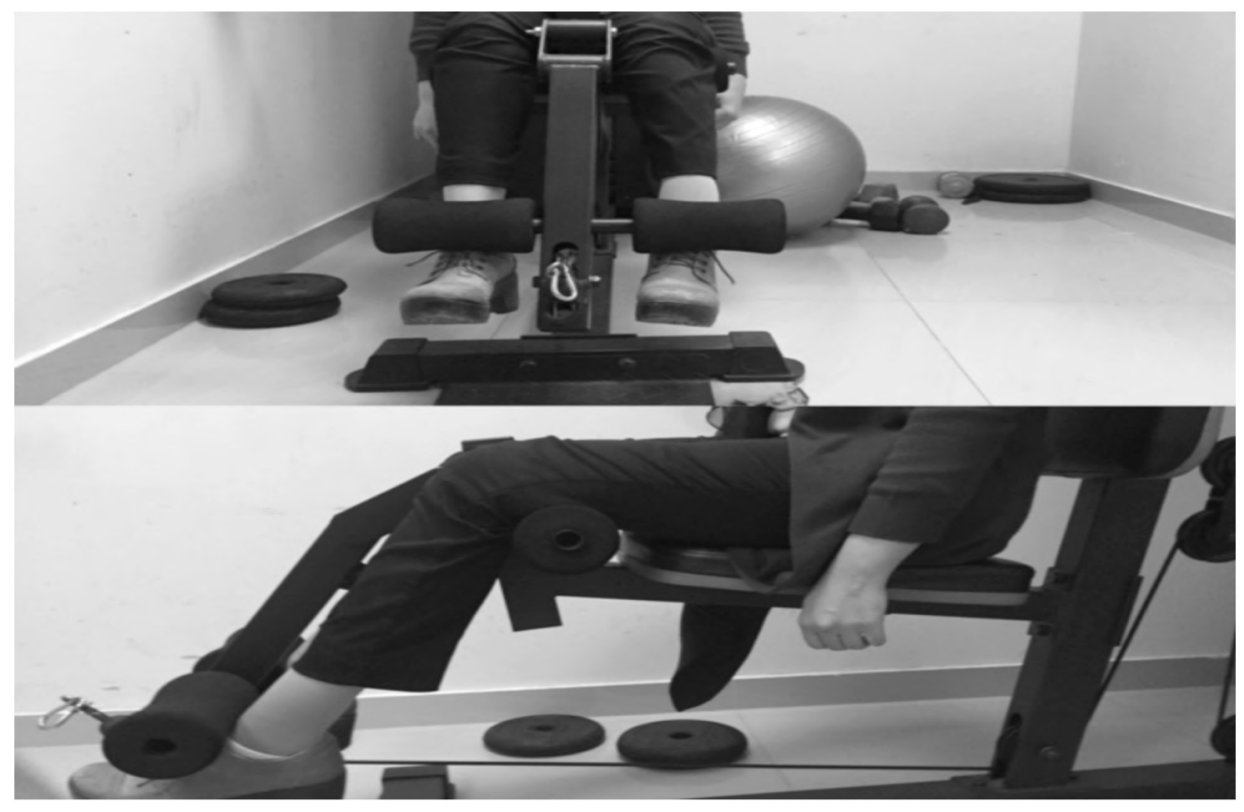

Fig. (2): Knee extension machine used for 1-RM Estimation.

Group A (conventional group): Patients assigned to this group received stretching and strengthening of the lower limb musculature (Appendix I), including HLR quadriceps exercises (60\% of 1RM) for a total of 12 treatment sessions ( 3 sessions per week) for 4 weeks [23].

Exercise 1: Straight leg raises (SLR) with ankle weight.

Exercise 2: Seated knee extension with ankle weight

Exercise 3: Hip abduction and adduction with ankle weight.

Exercise 4: Calf raises.

Exercise 5: Hamstring muscle stretch.

Group B (BFR group): Patients assigned to group $B$ received the same protocol but with LLR (30\% of 1RM) combined with BFR for a total of 12 treatment sessions (three sessions per week) for 4 weeks (Appendix II). The equipment used in BFR is a specially designed sphygmomanometer for lower limb that is able to restrict the thigh blood flow [24].

Exercise 1: SLRs with BFR using ankle weight.

Exercise 2: Seated knee extension with BFR using ankle weight.

Exercise 3: Hip abduction and adduction with BFR using ankle weight.

Exercise 4: Calf raises.

Exercise 5: Hamstring muscle stretch.

\section{Blood flow restriction cuff placement:}

Blood flow restriction was induced by using relatively narrow restrictive cuffs $5-6 \mathrm{~cm}$ width Restrictive cuff pressure between $160-240 \mathrm{mmHg}$ for the lower body is appropriate for most individuals. The device used was a specially designed sphygmomanometer for the lower limb. A pressure cuff inflated to $200 \mathrm{mmHg}$ during the quadriceps exercises was used [20] 
The distance from the inguinal crease to the top of the patella was measured using a measuring tape and a mark was made on the leg 33\% distal to the inguinal crease. Thigh circumference was measured at this mark to capture an accurate representation of the site at which the cuff would be placed. The device caused pooling of blood in vessels distal to the cuff [25].

Continuous rather than intermittent BFR during exercise was used. Continuous BFR is preferable to increase the metabolic demands and motor unit recruitment during LLR exercise [26].

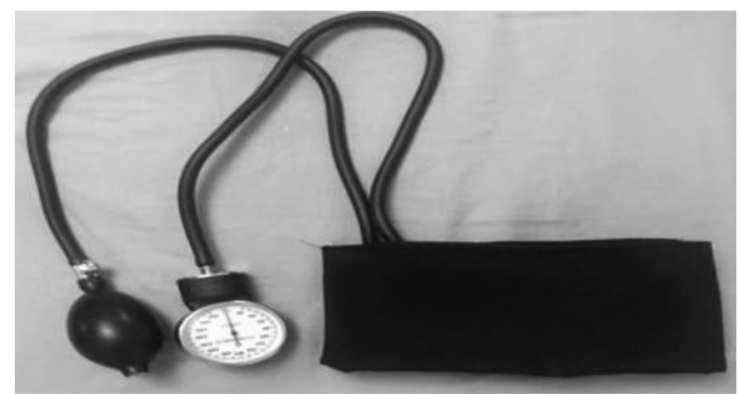

Fig. (3): Specially designed sphygmomanometer for the lower limb.

\section{Statistical analysis:}

Data were fed to the computer using SPSS software package version 20.0. Descriptive statistics were calculated for TUG in the form of mean \pm standard deviation.

For normally distributed data, comparison between both groups (A and B) was done using independent $t$-test while comparison between same group before and after treatment, unpaired $t$-test was used. Significance of the obtained results was judged at the $5 \%$ level.

\section{Results}

\section{General characteristics:}

The current study was conducted on 40 female patients suffering from mild to moderate degree knee OA. They were assigned randomly into two equal groups. As indicated by the independent $t$ test, there were no significant differences $(p>0.05)$ in the mean values of age and body mass index (BMI) between both tested groups (Table 1).

Table (1): Demographic data of Patients in both groups.

\begin{tabular}{lccc}
\hline Items & $\begin{array}{c}\text { Group A } \\
\text { Mean } \pm \text { SD }\end{array}$ & $\begin{array}{c}\text { Group B } \\
\text { Mean } \pm \text { SD }\end{array}$ & $\begin{array}{c}\text { Comparison } \\
p \text {-value }\end{array}$ \\
\hline Age (years) & $48.55 \pm 3.38$ & $48.85 \pm 3.23$ & 0.388 N.S \\
BMI $\left(\mathrm{kg} / \mathrm{m}^{2}\right)$ & $26.25 \pm 1.55$ & $26.21 \pm 1.57$ & 0.468 N.S \\
\hline Group A: Conventional group. & $\begin{array}{l}p \text { : Probability. } \\
\text { Group B: BFR group. }\end{array}$ & NS: Nonificance. \\
SD: Standard deviation. & NS: Nonificant.
\end{tabular}

Multiple pairwise comparison tests (Post hoc tests) for TUG test:

\section{1- Within groups:}

As presented in Table (2) and illustrated in Fig. (4), within group's comparison (the mean \pm SD) values of TUG test in the "pre" and "post" tests. Multiple pairwise comparison tests (Post hoc tests) revealed significant reduction of TUG test at post treatment compared to pretreatment ( $p$-value $=0.0001)$. While, the (mean $\pm \mathrm{SD})$ values of TUG test in the "pre" and "post" tests revealed that there was significant reduction of TUG test at post treatment when compared to pretreatment ( $p$-value $=0.0001$ ).

\section{2- Between groups:}

Considering the effect of the tested group on TUG test, Multiple pairwise comparison tests (Post hoc tests) revealed that the mean values of the "pre" test between both groups showed no significant differences with $(p=0.311)$. As well as, multiple pairwise comparison tests (Post hoc tests) revealed that there was no significant difference of the mean values of the "post" test between both groups with $(p=0.358)$.

Table (2): Mean \pm SD and $p$-values of TUG test pre and post treatment in both groups.

\begin{tabular}{|c|c|c|c|c|c|}
\hline $\begin{array}{l}\text { TUG } \\
\text { test }\end{array}$ & $\begin{array}{c}\text { Pre test } \\
\text { Mean } \pm \text { SD }\end{array}$ & $\begin{array}{c}\text { Post test } \\
\text { Mean } \pm \text { SD }\end{array}$ & MD & $\begin{array}{c}\% \text { of } \\
\text { change }\end{array}$ & $\begin{array}{c}p^{-} \\
\text {value }\end{array}$ \\
\hline Group I & $11.66 \pm 1.51$ & $9.63 \pm 1.36$ & -2.031 & -17.42 & $0.001 *$ \\
\hline Group II & $11.90 \pm 1.48$ & $9.48 \pm 1.21$ & -2.415 & -20.30 & $0.001 *$ \\
\hline MD & 0.235 & -0.149 & & & \\
\hline$p$-value & 0.311 & 0.358 & & & \\
\hline
\end{tabular}

SD : Standard deviation.

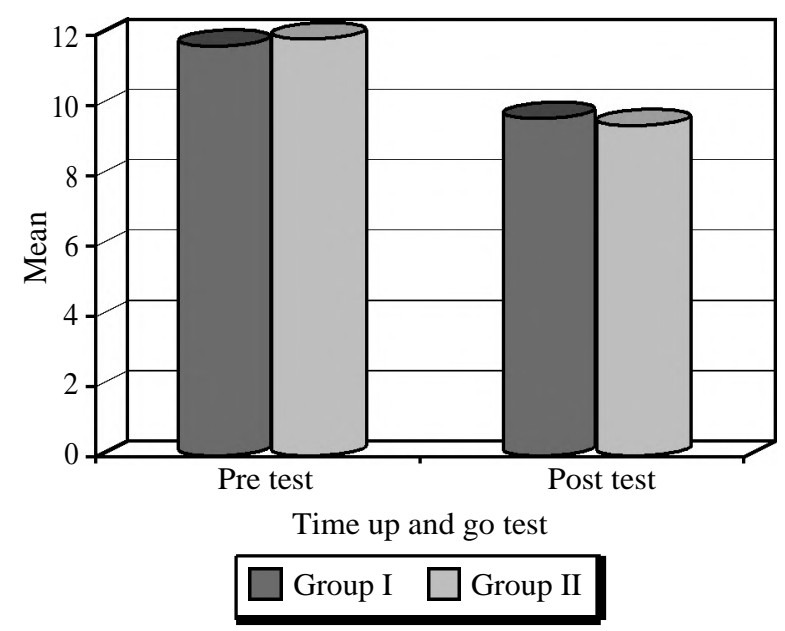

Fig. (4): Mean values of TUG test pre and post treatment in both groups. 


\section{Discussion}

Knee OA is characterized by pain, articular cartilage deterioration, joint space narrowing, and reduced muscle strength [27]. Knee pain during movement caused by OA is a strong predictor of an increased need for functional assistance [28] Loss of leg muscular strength is associated with increased pain and disability, as well as a more rapid progression of knee OA. Chronic kinematic alterations cause degenerative changes in the cartilage, particularly in older adults whose cartilage may no longer have the ability to adapt to load bearing. Pain, perceived instability, and functional limitations are common effects of this degenerative process [29].

Some authors had reported the clinical effectiveness of muscle strengthening exercises in patients with knee OA and have suggested that the exercise should not include high joint load [30]. If the knee joint is overloaded, patients with knee OA may aggravate symptoms such as pain, swelling, and inflammation [31]. However, other authors [32-34] have declared that strength training of a vigorous intensity (50\%-80\% of $1 \mathrm{RM})$ does not appear to induce or exacerbate joint symptoms in older adults.

Strength training, as recommended by the ACSM, must be performed at a minimum resistance training load of $60 \%$ to $70 \%$ 1-repetition maximum (1RM) for strength gain and $70 \%$ to $85 \% 1 \mathrm{RM}$ for muscle hypertrophy [10].

Augmented low-load resistance training with BFR is an alternative to traditional strength training that may be well tolerated by patients with knee OA [12]. Blood flow restriction is applied with the intent to promote blood pooling in the capillary beds of the limb musculature distal the tourniquet [13]. Loenneke et al., [35] reported that when BFR is combined with LLR training, it has been shown to result in similar muscular adaptations as higher load exercise.

Up to the authors' knowledge there was no previous study discussed the effect of LLR-BFR training on functional mobility in terms of TUG test with knee OA patients.

The effect of conventional HLR training on functional mobility in patients with knee OA:

The statistical analysis reported significant improvement of functional mobility when evaluated by TUG test after conventional HLR training.
The results of this study came into agreement with an RCT conducted by Jan et al., [36], they Investigated the clinical effects of high-and lowresistance training programs on 102 patients with mild to moderate knee OA. They found that both high and low resistance strength training significantly improved physical function. Although the effects of high-resistance strength training appear to be larger, the differences between both groups were not statistically significant.

A systematic review reviewed 18 RCTs with 2832 patients to assess the effectiveness of isolated resistance training on arthritis symptoms and physical performance in patients with knee OA. They concluded that resistance training improved physical function in patients with knee OA [37]

King et al., [38] conducted a clinical trial on 14 patients to evaluate the effect of a 12-week high intensity resistance training program on strength, pain, and function in patients with knee OA. There was a significant increase in the function subscale of the Knee Injury and Osteoarthritis Outcome Score (KOOS), and the Arthritis Self-Efficacy Scale (ASES).

On the contrary, a study done by Thorstensson et al., [39] was quite opposite to previously published studies on resistance exercise in knee OA. It aimed to test the effects of a short-term, highintensity exercise program on function and quality of life in sixty-one patients with knee OA with age range from 36-65. There was no improvement in pain or function, although some effects were seen on quality of life in the exercise group compared to the control group. Possible reasons for this difference may be due to patients with moderate to severe OA compared with mild to moderate in most previous studies, being younger than previously studied groups and the intervention being of comparably high intensity.

The effect of LLR-BFR training on functional mobility in patients with knee OA:

The statistical analysis reported significant improvement of functional mobility when evaluated by TUG test after LLR-BFR training.

Yokokawa et al., [40] conducted a study to compare the effect of LLR training with BFR versus dynamic balance exercise in elderly people at risk of knee OA. Fifty-one subjects aged 65 and older were randomly assigned to one of two groups. Performance was assessed in both groups before and after the 8-week programs. In addition, blood was sampled from LIO participants $(\mathrm{n}=11)$ and 
analyzed for growth hormone and lactate. Overall improvements, but no group differences, were found in performance and balance after the programs. TUG test was used to evaluate functional mobility.

Bryk et al., [23] conducted a clinical trial to evaluate whether 34 patients with mean age 61 years old with knee OA performing a rehabilitation program consisting of low-load exercises combined with partial vascular occlusion exhibited the same results in functional improvement when compared to women receiving a program consisting of high load exercises. After a program of 6 weeks functional performance was tested using TUG. Results showed that a rehabilitation program that combined partial vascular occlusion to low-load exercise resulted in similar benefits in function to a program using high-load exercise in patients with knee OA.

\section{Conclusion:}

Based on the findings of the present study the following can be concluded:

Adding BFR to LLR exercise resulted in similar benefits in functional mobility to that of high-load conventional exercise programs in women with knee OA this kind of exercise is beneficial to patients who had a perceived reduced tolerance of the high-load programs Thus, it may be a good exercise form for enhancing physical function and effectively strengthening the quadriceps muscles while limiting pain and adverse joint loading in people with knee OA.

\section{Recommendations:}

- Further studies are needed with other outcomes on the effect of LLR combined with BFR on patients with knee OA.

- Further studies are needed to evaluate the effect of BFR when added to any other kind of therapeutic exercises.

- Further studies are needed to evaluate the effect of BFR on other musculoskeletal disorders.

- Further study should be performed with a larger sample size and long term follow-up.

\section{Limitation:}

Our study was limited to:

- Duration of follow-up.

\section{References}

1- TROJIAN T., CONCOFF A., JOY S., HATZENBUEHLER J., SAULSBERRY W. and COLEMAN C.: AMSSM scientific statement concerning viscosupplementation injections for knee osteoarthritis: Importance for individual patient outcomes. British Journal of Sports Medicine, 50 (2): 84-92, 2016.

2- BRUYÈRE O., COOPER C., PELLETIER J., BRANCO J., BRANDI M.L., GUILLEMIN F. and RIZZOLI R.: An algorithm recommendation for the management of knee osteoarthritis in Europe and internationally: A report from a task force of the European Society for Clinical and Economic Aspects of Osteoporosis and Osteoarthritis (ESCEO). In Seminars in Arthritis and Rheumatism, 44 (3): 253-263, 2014.

3- MURPHY L., SCHWARTZ T., HELMICK C., RENNER J., TUDOR G., KOCH G. and JORDAN J.: Lifetime risk of symptomatic knee osteoarthritis. Arthritis Care and Research, 59 (9): 1207-1213, 2008

4- SEGAL N., GLASS N., FELSON D., HURLEY M. YANG M., NEVITT M. and TORNER, J.The effect of quadriceps strength and proprioception on risk for knee osteoarthritis. Medicine and Science in Sports and Exercise, 42 (11): 2081, 2010.

5- BAKER K., XU L., ZHANG, Y., NEVITT M., NIU, J., ALIABADI, P. and FELSON D.: Quadriceps weakness and its relationship to tibiofemoral and patellofemoral knee osteoarthritis in Chinese: The Beijing osteoarthritis study. Arthritis and Rheumatism, 50 (6): 1815-1821, 2004.

6- SEGAL N., TORNER J., FELSON D., NIU J., SHARMA L., LEWIS C. and NEVITT M.: Effect of thigh strength on incident radiographic and symptomatic knee osteoarthritis in a longitudinal cohort. Arthritis Care \& Research, 61 (9): 1210-1217, 2009.

7- SEGAL N., WILLIAMS G., DAVIS M., WALLACE R. and MIKESKY A.: Efficacy of Blood Flow-Restricted, Low-Load Resistance Training in Women with Risk Factors for Symptomatic Knee Osteoarthritis. PM. and R., 7 (4): 376-384, 2015.

8- MCALINDON T., BANNURU R., SULLIVAN M., ARDEN N., BERENBAUM F., BIERMA-ZEINSTRA S. and KWOH K.: OARSI guidelines for the non-surgical management of knee osteoarthritis. Osteoarthritis and Cartilage, 22 (3): 363-388, 2014

9- VINCENT K., VINCENT H., RESISTANCLANGE A and VANWANSEELE B.: Strength training for treatment of osteoarthritis of the knee: A systematic review. Arthritis Care and Research, 59 (10): 1488-1494, 2008.

10- STAND P.: Progression models in resistance training for healthy adults. Medicine and Science in Sports and Exercise, 41 (3): 687-708, 2009.

11- MESSIER S., MIHALKO S., BEAVERS D., NICKLAS B., DEVITA P., CARR J. and LYLES M.: Strength Training for Arthritis Trial (START): Design and Rationale. BMC Musculoskeletal Disorders, 14 (1): 208, 2013.

12- POPE Z., WILLARDSON J. and SCHOENFELD B. Exercise and blood flow restriction. Strength. Cond. Res. J., 27 (10): 2914-2926, 2013.

13- SLYSZ J., STULTZ J. and BURR J.: The efficacy of blood flow restricted exercise: A systematic review and meta-analysis. Journal of Science and Medicine in Sport, 19 (8): 669-675, 2016.

14- KUBOTA A., SAKURABA K., SAWAKI K., SUMIDE T. and TAMURA Y.: Prevention of disuse muscular weak- 
ness by restriction of blood flow. Medicine and Science in Sports and Exercise, 40 (3): 529-534, 2008.

15- LOENNEKE J., WILSON J., WILSON G., PUJOL T. and BEMBEN M.: Potential safety issues with blood flow restriction training. Scandinavian Journal of Medicine and Science in Sports, 21 (4): 510-518, 2011.

16- MADARAME H., NEYA M., OCHI E., NAKAZATO K., SATO Y. and ISHII N.: Cross-transfer effects of resistance training with blood flow restriction. Medicine+Science in Sports+Exercise, 40 (2): 258, 2008.

17- ABE T., SAKAMAKI M., FUJITA S., OZAKI H., SUGAYA M., SATO Y. and NAKAJIMA T.: Effects of lowintensity walk training with restricted leg blood flow on muscle strength and aerobic capacity in older adults. Journal of Geriatric Physical Therapy, 33 (1): 34-40, 2010.

18- YASUDA T., FUJITA S., OGASAWARA R., SATO Y. and ABE T.: Effects of low-intensity bench press training with restricted arm muscle blood flow on chest muscle hypertrophy: A pilot study. Clinical Physiology and Functional Imaging, 30 (5): 338-343, 2010.

19- SOUSA J., NETO G., SANTOS H., ARAÚJO J., SILVA H. and CIRILO-SOUSA M.: Effects of strength training with blood flow restriction on torque, muscle activation and local muscular endurance in healthy subjects. Biology of Sport, 34 (1): 83, 2017.

20- CLARK B., MANINI T. , HOFFMAN R., WILLIAMS P., GUILER M., KNUTSON M. and KUSHNICK M.: Relative safety of 4 weeks of blood flow-restricted resistance exercise in young, healthy adults. Scandinavian Journal of Medicine and Science in Sports, 21 (5): 653-662, 2011.

2 1= GAUTSCHI O.P., CORNIOLA M.V., JOSWIG H., SMOLL N.R., CHAU I., JUCKER D. and STIENEN M.N.: The timed up and go test for lumbar degenerative disc disease. Journal of Clinical Neuroscience, 22 (12): 1943-1948, 2015

22- KRAEMER W., ADAMS K., CAFARELLI E., DUDLEY, G., DOOLY C., FEIGENBAUM M. and NEWTON R. American college of sports medicine position stand. progression models in resistance training for healthy adults. Medicine and Science in Sports and Exercise, 34 (2): 364-380, 2002.

23- BRYK F., DOS REIS A., FINGERHUT D., ARAUJO T., SCHUTZER M., CURYR D. and FUKUD T.: Exercises with partial vascular occlusion in patients with knee osteoarthritis: a randomized clinical trial. Knee Surgery, Sports Traumatology. Arthroscopy, 24 (5): 1580-1586, 2016.

24- LIBARDI C., CHACON-MIKAHIL M., CAVAGLIERI C., TRICOLI V., ROSCHEL H., VECHIN F. and UGRINOWITSCH C.: Effect of concurrent training with blood flow restriction in the elderly. International Journal of Sports Medicine, 2015.

25- LOENNEKE J., THIEBAUD R., FAHS C., ROSSOW L., ABE T. and BEMBEN M.: Blood flow restriction: Effects of cuff type on fatigue and perceptual responses to resistance exercise. Acta Physiologica Hungarica, 101 (2): 158 166, 2014.

26- FAHS C., LOENNEKE J., ROSSOW L., TIEBAUD R. and BEMBEN M.: Methodological considerations for blood flow restricted resistance exercise. Journal of Trainology, 1 (1): 14-22, 2012.
27- GARSTANG S. and STITIK T.: Osteoarthritis: Epidemiology, risk factors, and pathophysiology. American journal of physical medicine and rehabilitation, 85 (11): 2-11, 2006.

28- JINKS C., JORDAN K. and CROFT P.: Osteoarthritis as a public health problem: The impact of developing knee pain on physical function in adults living in the community : (KNEST 3). Rheumatology, 46 (5): 877-881, 2007.

29- VINCENT K. and VINCENT H.: Resistance exercise for knee osteoarthritis. PM. and R., 4 (5): 45-52, 2012.

30- KETTUNEN J. and KUJALA U.: Exercise therapy for people with rheumatoid arthritis and osteoarthritis. ScanDinavian Journal of Medicine and Science in Sports, 14 (3): 138-142, 2004.

31- BALIUNAS A., HURWITZ D., RYALS A., KARRAR A., CASE J., BLOCK J. and ANDRIACCHI T.: Increased knee joint loads during walking are present in subjects with knee osteoarthritis. Osteoarthritis and Cartilage, 10 (7): 573-579, 2002.

32- NICHOLS J., OMIZO D., PETERSON K. and NELSON K.: Efficacy of heavy-resistance training for active women over sixty: Muscular strength, body composition, and program adherence. Journal of the American Geriatrics Society, 41 (3): 205-210, 1993.

33- COLEMAN E., BUCHNER D., CRESS M.., CHAN B. and LATEUR B.: The relationship of joint symptoms with exercise performance in older adults. Journal of the American Geriatrics Society, 44 (1): 14-21, 1996.

34- HÄKKINEN K. and HÄKKINEN A.: Neuromuscular adaptations during intensive strength training in middleaged and elderly males and females. Electromyography and Clinical Neurophysiology, 35 (3): 137-147, 1995.

35- LOENNEKE J., FAHS C., ROSSOW L., SHERK V., THIEBAUD R., ABE T. and BEMBEN M.: Effects of cuff width on arterial occlusion: Implications for blood flow restricted exercise. European Journal of Applied Physiology, 112 (8): 2903-2912.

36- JAN M., LIN J., LIAU J.J., LIN Y. and LIN D.: Investigation of clinical effects of high-and low-resistance training for patients with knee osteoarthritis: A randomized controlled, 2008

37- LANGE A. and VANWANSEELE B.: Strength training for treatment of osteoarthritis of the knee: A systematic review. Arthritis care and Research, 59 (10): 1488-1494, 2008.

3 8- KING L., BIRMINGHAM T., KEAN C., JONES I., BRYANT D. and GIFFIN J.: Resistance training for medial compartment knee osteoarthritis and malalignment. Medicine and Science in Sports and Exercise, 40 (8): 1376-1384, 2008.

39- THORSTENSSON C., ROOS E., PETERSSON I. and EKDAHL C.: Six-week high-intensity exercise program for middle-aged patients with knee osteoarthritis: A randomized controlled trial. BMC Musculoskeletal Disorders, 6 (1): 27,2005

40- YOKOKAWA Y., HONGO M., URAYAMA H., NISHIMURA T. and KAI I.: Effects of low-intensity resistance exercise with vascular occlusion on physical function in healthy elderly people. Biosci Trends, 2 (3): 117-123, 2008. 


\section{Appendix I}

\section{Exercises performed in the conventional group}

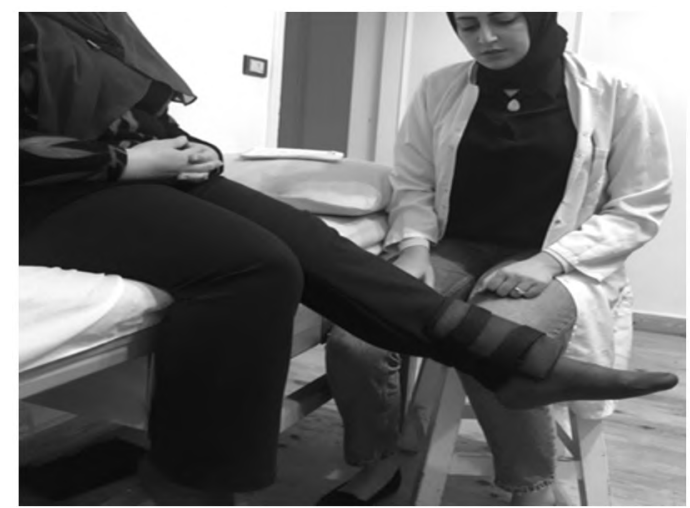

Fig. (1): Seated quadriceps knee extension with ankle weight.

Sitting with knee at $90^{\circ}$ flexion, the patient was asked to fully extend the knee. Resistance $(60 \%$ 1RM) was provided by ankle weights ( 3 sets of 10 repetitions).

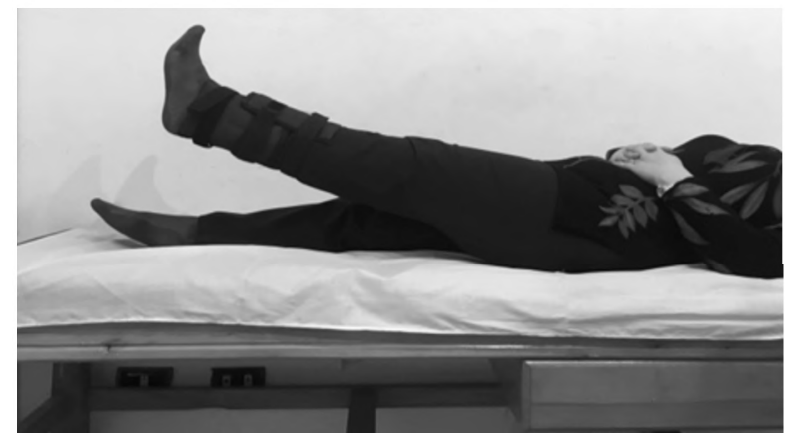

Fig. (2): Straight leg raising with ankle weight

In a supine position, the patient was asked to raise the exercise limb with the knee in full extension, and then lower the limb back to the initial position; resistance $(60 \% 1 \mathrm{RM})$ was provided by ankle weights (3 sets of 10 repetitions).

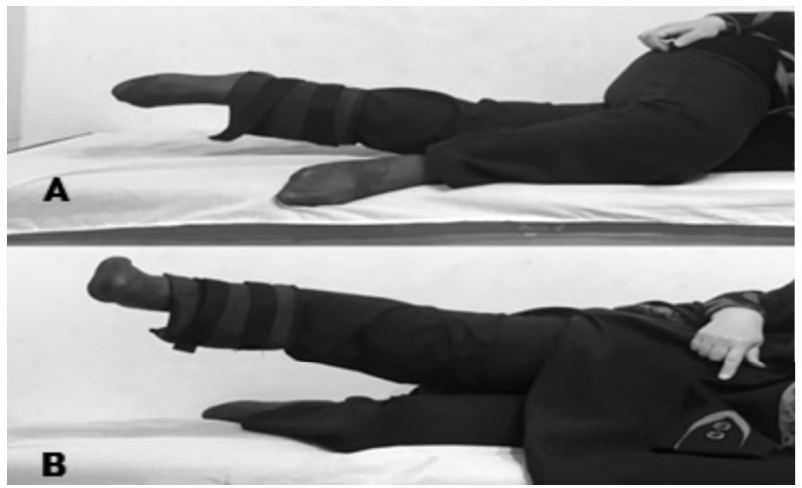

Fig. (3): Hip abduction and adduction from side lying position using ankle weights.
3A- Lying sideways, the patient was asked to bend the hip and the knee of the upper leg and raise the lower leg, keeping it straight; extra resistance $(60 \% 1 \mathrm{RM})$ was provided by ankle weights ( 3 sets of 10 repetitions).

3B- Lying sideways, the patient was asked to bend the knee and hip of the lower leg and raise the upper leg, keeping it straight; extra resistance $(60 \%$ 1RM) was provided ankle weights ( 3 sets of 10 repetitions).

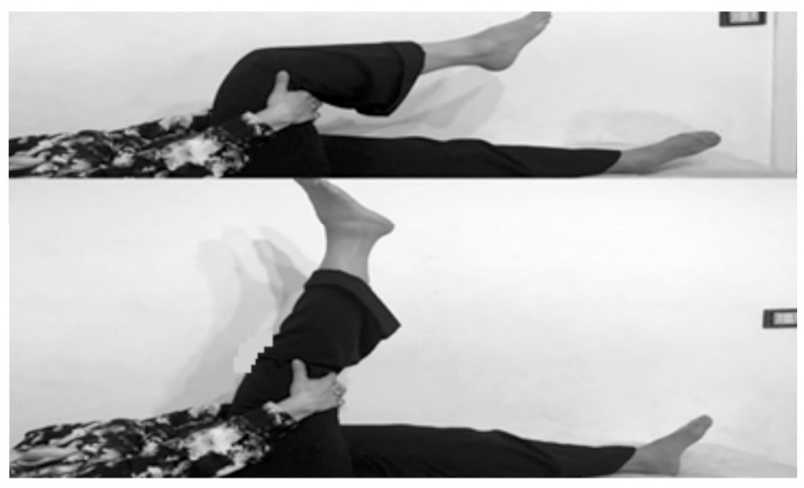

Fig. (4): Hamstring muscle stretching.

In a supine position, the patient was asked to raise the exercise limb with the hip and knee in $90^{\circ}$ flexion then the patient was asked to extend the knee fully while holding the thigh (3 repetitions for $30 \mathrm{~s}$ ).

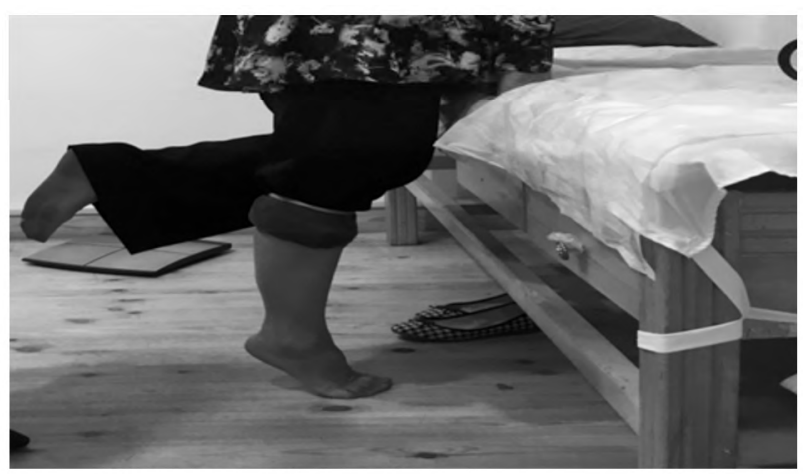

Fig. (5): Unilateral calf raise.

In a standing position, patient was asked to rise up on toes and return (3 sets of 10 repetitions). 


\section{Appendix II}

\section{Exercises performed in the BFR group}

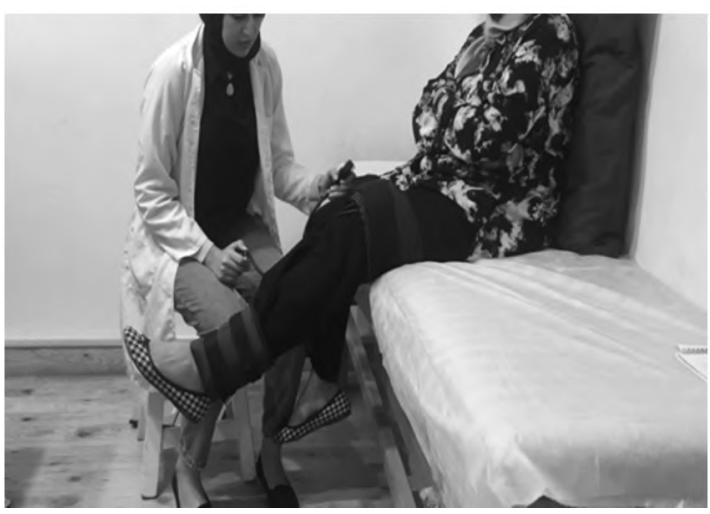

Fig. (6): Seated quadriceps knee extension using ankle weight with BFR.

Patient was asked to sit with knee at $90^{\circ}$ flexion. The BFR device was applied distal to the inguinal crease and the pressure cuff was inflated to 200 $\mathrm{mmHg}$ the patient was asked to fully extend the knee. Resistance (30\% 1RM) was provided by ankle weights (3 sets of 10 repetitions).

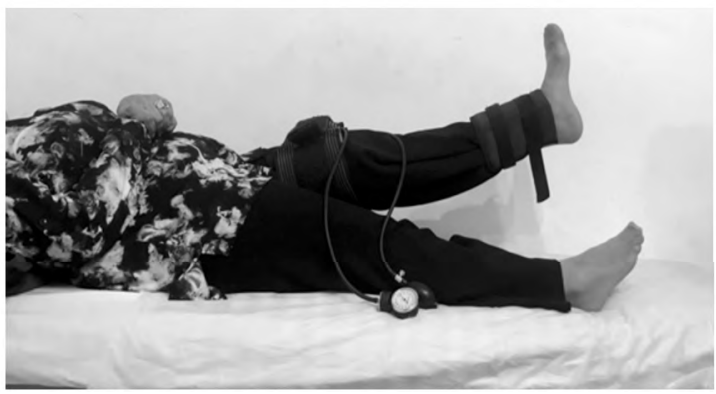

Fig. (7): Seated quadriceps knee extension using ankle weight with BFR.

In a supine position, The BFR device was applied distal to the inguinal crease and the pressure cuff was inflated to $200 \mathrm{mmHg}$. The patient was asked to raise the exercise limb with the knee in full extension, and then lower the limb back to the initial position; resistance (30\% 1RM) was provided by ankle weights (3 sets of 10 repetitions).

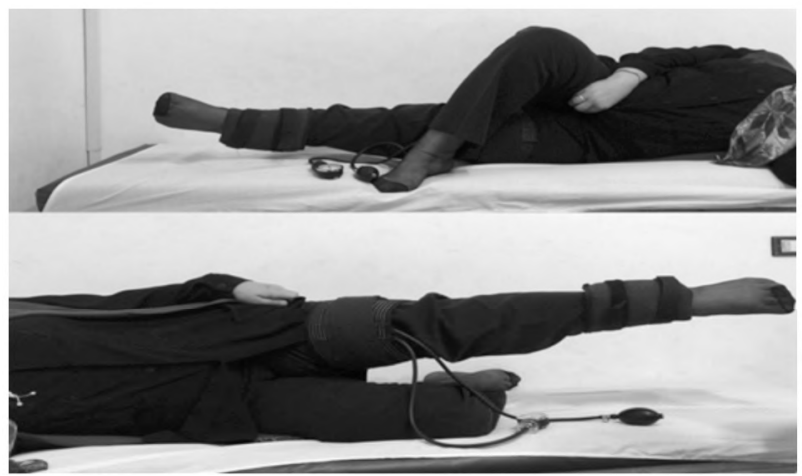

Fig. (8): Hip abduction and adduction from side lying position using ankle weights with BFR.
8A- Lying sideways, The BFR device was applied distal to the inguinal crease and the pressure cuff was inflated to $200 \mathrm{mmHg}$. The patient was asked to bend the hip and the knee of the upper leg and raise the lower leg, keeping it straight; resistance ( $30 \%$ 1RM) was provided by ankle weights ( 3 sets of 10 repetitions).

8B- Lying sideways, The BFR device was applied distal to the inguinal crease and the pressure cuff was inflated to $200 \mathrm{mmHg}$. The patient was asked to bend the knee and hip of the lower leg and raise the upper leg, keeping it straight; resistance (30\% 1RM) was provided by ankle weights (3 sets of 10 repetitions).

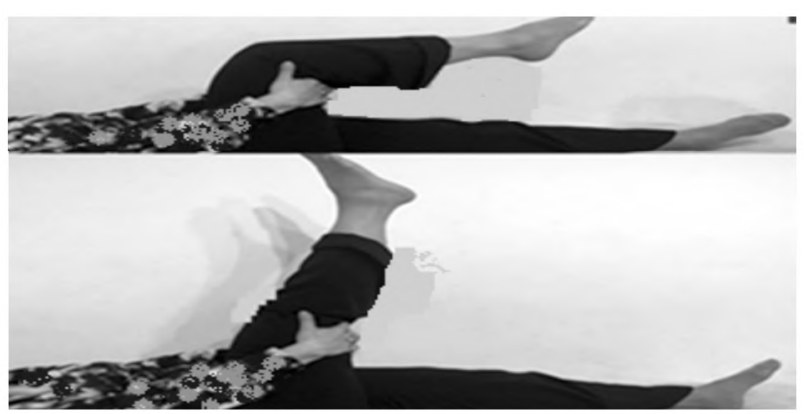

Fig. (9): Hamstring muscle stretching.

In a supine position, the patient was asked to raise the exercise limb with the hip and knee in $90^{\circ}$ flexion then the patient was asked to extend the knee fully while holding the thigh (3 repetitions for 30 s).

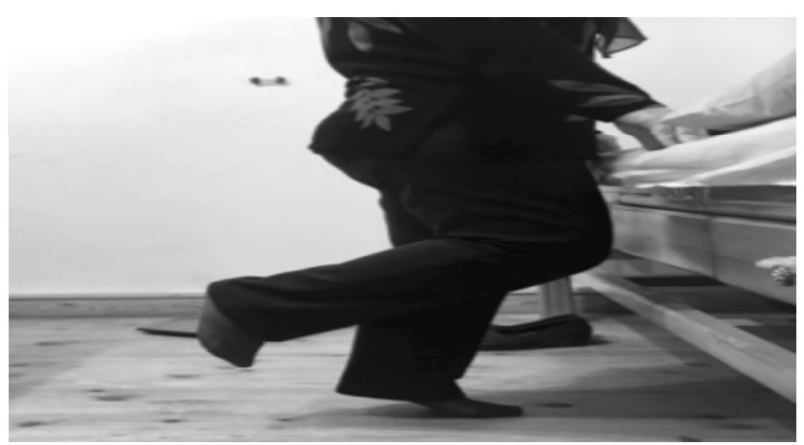

Fig. (10): Hip abduction and adduction from side lying position using ankle weights with BFR.

In a standing position, patient was asked to rise up on toes and return ( 3 sets of 10 repetitions). 


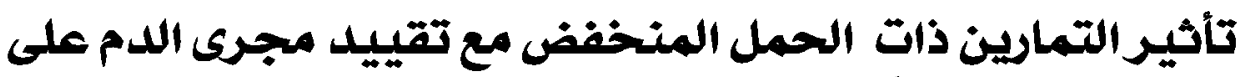 الألتهاب العظمى الهمل المفصلى للركبية}

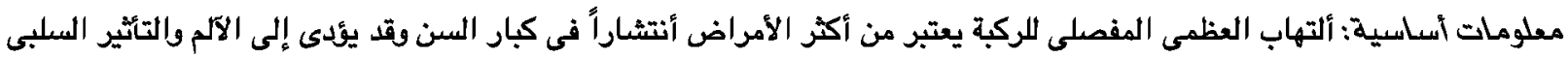

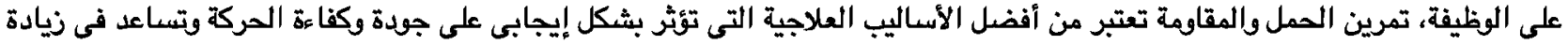

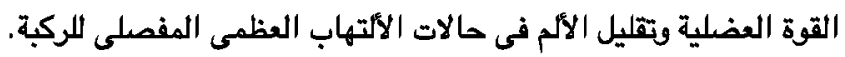

الهدف: وقد أجريت هذه الدراسة للمقارية بين تأثير التمارين ذات الحمل المنخفض مع تقييد مجرى الدم والتمارين ذات الصمل المرتفع على الأداء الوظيفى عن طريق أختبار توقيت النهوض والحفي آهركة على الألتهاب العظمى المفصلى للركبة.

الأسـاليب والمرضى : أجريت هذه الدراسة على أربعين مريضاً يعانون منإلتهاب العظمى المفصلى للركية وكان متوبسط العمر من خمسة

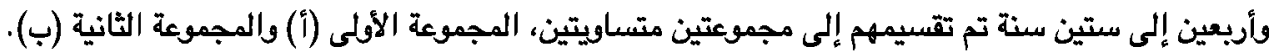

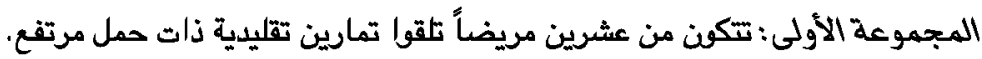

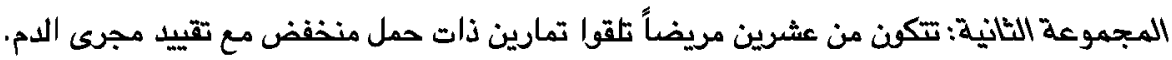
طريقة القياس: تم تقييم الأداء الوظيفى عن طريق أختبار (توقيت النهوض والحركة). أظهرت النتائج وجود تصسن فى المجوعتين الأولى والثانية، مع العلم أن الآلام الأمامية للركبة كانت أقل من المجموعة الثانية بالمقارنة مـ المجموعة الأولى.

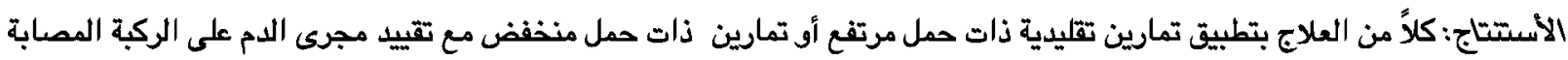

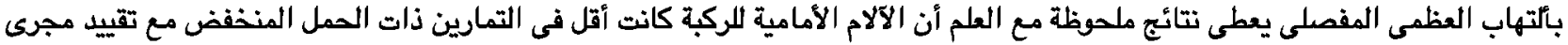

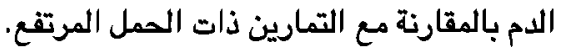

